\title{
SPACE PLANNING WITH GREEN PERSPECTIVE
}

\author{
Yingchun $\mathrm{Hsu}^{*}$ \\ Digital Design, Skidmore Owings \& Merrill LLP, Chicago, USA \\ * Corresponding author (yingchunhsu@gmail.com)
}

\begin{abstract}
As technology progresses and software developer's increasing effort, we can foresee that the bi-directional procedures between design/analysis platforms will be shorten dramatically over time to improve the efficiency of building model analysis. But how about the decision-making phase that even before models been built for analysis? By adopting the Space Dynamic Behavior algorithm, a new "green, energy-saving” layer of information can be added on top of space adjacency information in the space-planning system and generates "Green" spatial plans. These Green plans, differ from the basic space plans, inherit energy-saving concepts including daylight impact, energy consumption period and more; which provide designers planning options in the green aspect.
\end{abstract}

Keywords: Space Planning, Space Dynamic Behavior, Form Generation, Bubble Diagram, Energy Saving

\section{INTRODUCTION}

"Green building”, "LEED certified" became the buzz words for the past couple of years in architectural design and research. Many approaches have been proposed to save energy with the assistance of analysis software, which offers designers to understand the impact from the environment and the energy consumptions from different design options. Various modeling/analysis platforms are developed and refined specifically for this purpose, as well as the communication/transition procedure between these platforms.

As technology progresses and software developer's increasing effort, we can foresee that the bi-directional procedures between design/analysis platforms will be shorten dramatically over time to improve the efficiency of building model analysis. But how about the decisionmaking phase that even before models been built for analysis? With rich environmental information that is offered from current design software, how can the design tools offer more to assist designers during the spaceplanning process or form studying, or even generate possible solutions to designers with energy-saving in "mind”?
During the conceptual design, architects typically arrange the space bubble/block diagrams according to the project criteria, clients request and personal experiences in spaceplanning phase and then create 3D models for further study. In this case, the 3D model is used for energy analysis and the feedback will be included for the consideration of design change. The architects that pursue green building ideas not only will change the building envelops and materials to reach the energy-saving goal, but would/should deliver the concept via space-planning programs as well.

\section{SPACE DYNAMIC BEHAVIOR}

In the book "Visualizing the Concept and Beyond Integrated Space Planning Technology with Form Generation” [1], the author proposed the Space Dynamic Behavior algorithm that provides the decision-making process of space-planning a portal to explore different design options. This algorithm proposed seven generic categories of "characters" for designers to assign to spaces, which leads the spaces to interact with other spaces and environmental elements, and generate space layouts (Fig. $1)$. 


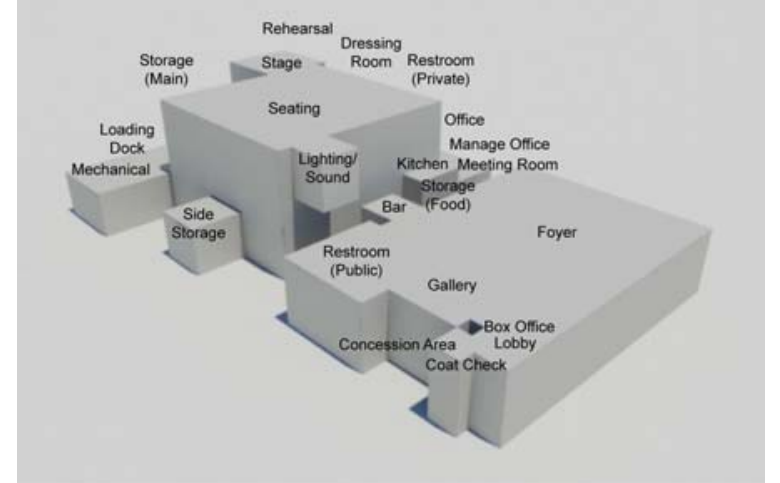

Fig. 1 Block diagram generated with Space Dynamic Behavior algorithm.

At the later stage of form study, different characters can be assigned with various form elements to generate conceptual forms that related with the space programs (Fig. 2).

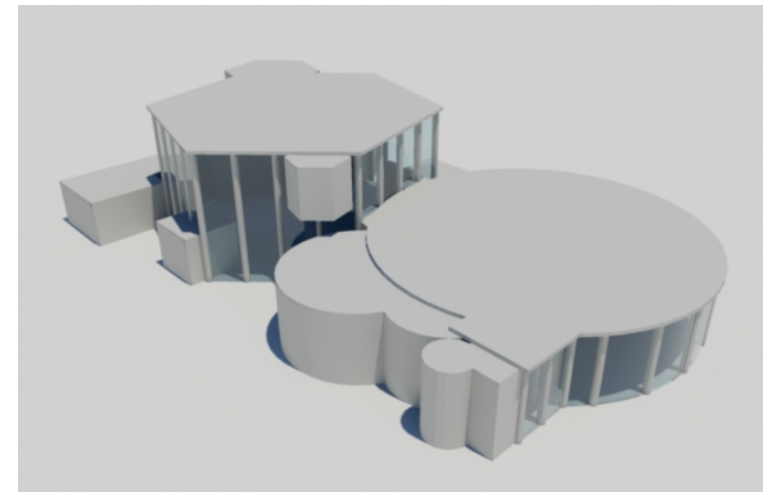

Fig. 2 Conceptual form options generated with form elements assigned to Spatial Characters.

These spatial characters can be divided to two categories: Internal space dynamics and external attractions. The dynamic behaviors, mimicking the space-planning technique by architects, are based on the functions of spaces and preferences of clients and designers.

\section{“GREEN” SPATIAL BEHAVIOR}

By adopting this algorithm, a new "green, energy-saving" layer of information can be defined as a new category of space characters. By linking the natural resources (i.e. sun light) to the environmental elements in this algorithm, the new "Green Spatial Characters" will attract or avoid the certain orientation to achieve energy saving goals. Further research can be conducted to explored various energysaving scenarios and develop more types of spatial behaviors.

With the energy-saving consideration added on top of space adjacency information, the “Green” spatial plans will be generated by the space-planning system. These Green plans, differ from the basic space plans, inherit energysaving concepts including daylight impact, energy consumption period and more; which provide designers planning options in the green aspect. This information may be reserved in the Building Information Model for future facility management purposes.

\section{REFERENCES}

[1] Hsu, Y., "Visualize the Concepts and Beyond", VDM Verlag Dr. Mueller e.K., pp. 67, 214, 218, 2008. 